$\mathrm{K}, \mathrm{Rb}$ and $\mathrm{Cs}$ the consequences are at once numerous and far reaching. First, the relative depletion of the three elements in the lithosphere becomes immediately explicable; and the terrestrial abundances of the major elements become compatible with a chondritic source. Second, it is no longer necessary to invoke volatilization during high temperature accretion to account for the apparent disappearance of terrestrial potassium and sulphur. Third, it may no longer be necessarily true that the chondritic Earth model, which explains the observed terrestrial heat flow so well, is not valid simply because the crust and mantle do not contain enough $\mathrm{K}, \mathrm{U}$ and $\mathrm{Th}$. Fourth, as much as seven eighths of the ${ }^{40} \mathrm{~K}$ in the Earth may be in the core, thereby forming a major heat source of about $10^{20} \mathrm{ergs} \mathrm{s}^{-1}$. Even if the efficiency of conversion is only $10^{-4}$ there would be enough energy here to maintain the convection to produce the geomagnetic field.

The fifth point is that the rough equality of oceanic and continental heat flow, notwithstanding the greater concentration of radioactive heat-producing minerals in the continental crust, may be explained by convective upwelling of deep ${ }^{40} \mathrm{~K}$ beneath the oceans. Sixth, the low abundance of ${ }^{40} \mathrm{Ar}$ in the atmosphere compared with the abundance to be expected from the decay of ${ }^{40} \mathrm{~K}$ in a completely degassed chondritic Earth could be related to the impossibility of degassing radiogenic ${ }^{10} \mathrm{Ar}$ from the core. And, finally, the low abundance of ${ }^{87} \mathrm{Sr}$ in the crust may be the result of the removal to the core of much of the Rb early in the Earth's evolution.

But can so many consequences, covering, as they do, such a wide range of geophysical and geochemical problems, really stem from such a simple premise? It is possible, of course, that Lewis has underestimated the complexity of some of the problems his basic thesis purports to solve. Even so, his wideranging conclusions must surely force a re-evaluation of the problems which have turned most scientists away from the simple chondritic Earth.

\section{PESTICIDES}

\section{Leaching from Soil}

from a Correspondent

IT is well known that fish and other aquatic organisms may concentrate organochlorine pesticides from very low levels in the water in which they swim until the amounts in their bodies are either lethal or too high for the fish to be eaten by man, so that this form of environmental contamination has received considerable study. The 1970 report of the Agricultural Research Council's Research Committee on Toxic
Chemicals showed that some organochlorine pesticides were likely to come from rainfall, but that factory effluents and accidents such as spills of sheep dip were more important. Measurable amounts of pesticides are washed off the surface of treated fields especially by flash floods, but "underground water, which has percolated through soil, has not been found to contain measurable quantities of organochlorines".

This conclusion is based on many observations, mostly in temperate countries. The British Ministry of Agriculture suffered some criticism for suggesting that the best way of disposing of surplus and unwanted DDT, shortly to be banned for use in gardens in Britain following the recommendations of the Advisory Committee on Pesticides and Other Toxic Chemicals (the Wilson Committee), was to rotovate it into the soil, though this is, in Britain, a method which is likely to localize the insecticide's effects, and is far safer than such methods as disposal down the drain, or bulk burial.

A disquieting report from Pakistan is contained in an article by Aslam I. Nasim, M. M. H. Baig and K. A. Lord, of the Toxicology and Pesticide Laboratory, Karachi (Envir. Poll., 2, 1 ; 1971).
These authors have found that organochlorine insecticides are widely distributed in soils in East Pakistan and are extracted by water from the soil. Nasim et al. examined six soil samples from three different localities near Dacca by silica-loaded paper and gas chromatography and found that all were contaminated with organochlorine insecticides and contained 1 to 3 p.p.m. of DDT. Furthermore, three of the samples contained 0.1 to 0.5 p.p.m. gamma BHC and three others about 0.5 p.p.m. dieldrin. $\mathrm{BHC}$ has been used in the past in Pakistan for the control of rice pests and dieldrin is used in the treatment of bamboo, but there seems to be no easy explanation for the DDT contamination.

Because insecticides are leached from soil by water, the presence of 1 to 3 p.p.m. of DDT and other insecticides in the soils examined by Nasim et al. could pose a threat to the fish life inhabiting paddy fields as well as the more direct contamination of water sources. Nasim et al. consider it essential therefore that further monitoring continues-freshwater fish are important sources of protein for the population of East Pakistan, and any deleterious effects of the insecticides on the fish populations could be serious.

\title{
Hormone-responsive Tumours
}

A FAvourite pastime of steroid endocrinologists in recent months has been hunt-the-receptor-protein, and attention is now turning towards the determination of the physiological relevance of these proteins. One aspect of this concerns their role in steroidcontrolled growth of certain tumours. In general, hormone responsive tumours show a progression from a responsive to an unresponsive state, and this is associated with a loss or diminution of specific steroid-binding capacity (King, Smith and Steggles, Steroidologia, 1, $73 ; 1970)$.

In next Wednesday's Nature New Biology, Kirkpatrick, Milholland and Rosen report a decreased amount of corticosteroid receptor in unresponsive P1798 lymphosarcoma as compared with the corticosteroid-responsive line. This confirms the earlier work of Hollander and Chiu (Biochem. Biophys. Res. Commun., 25, 291; 1966), but Kirkpatrick and his colleagues have taken advantage of a factor not usually available in this type of work, that a parallel biochemical response (DNA synthesis and membrane permeability) can be measured as an indication of the relevance of the steroid protein interaction. They also show that, contrary to one of the current vogues of cancer research. changes in the cell membrane cannot explain their results.
An unanswered question is what or where is the primary lesion causing this loss? Recent reports indicate that steroid specificity is controlled at the nuclear level as well as by the presence of a cytoplasmic protein (Steggles, Spelsberg, Glasser and O'Malley, Proc. US Nat. Acad. Sci., 68, 1479 ; 1971) so it is possible that a change in binding may also occur at the nuclear level. Kirkpatrick et al. found that nuclear binding was low in the responsive cells, but do not mention the unresponsive ones.

A study such as this has several aspects that are relevant to tumour biology. First, it indicates that receptors are involved in steroid mediated inhibitory as well as activation processes. Second, it suggests that receptors may be translatable into clinical tests for the hormone responsiveness of human tumours; it is of considerable practical importance to decide which breast cancer patients will benefit from ablative endocrine surgery and oestrogen-binding experiments look hopeful in this respect. Third, the presence of a regulatory protein in a responsive cell and its loss or diminished binding potential in unresponsive cells (none of the experiments distinguishes between these two possibilities) have obvious analogies with enzyme induction in microorganisms. 